\title{
Study of the Properties of In Vitro Dactylorhiza maculata (L.) Soó (Family Orchidaceae) Extracts
}

\author{
Stanislav Sukhikh ${ }^{1,2}$, Svetlana Noskova ${ }^{1}$, Svetlana Ivanova ${ }^{3,4, *}{ }^{\mathbb{C}}$, Liubov Skrypnik ${ }^{1}{ }^{\circledR}$, Artem Pungin ${ }^{1}$, \\ Elena Ulrikh ${ }^{5}$, Evgeny Chupakhin ${ }^{1}$ (D) and Olga Babich ${ }^{1}$ (D) \\ 1 Institute of Living Systems, Immanuel Kant Baltic Federal University, A. Nevskogo Street 14, \\ 236016 Kaliningrad, Russia; stas-asp@mail.ru (S.S.); svykrum@mail.ru (S.N.); LSkrypnik@kantiana.ru (L.S.); \\ apungin@kantiana.ru (A.P.); chupakhinevgen@gmail.com (E.C.); olich.43@mail.ru (O.B.) \\ 2 Department of Bionanotechnology, Kemerovo State University, Krasnaya Street 6, 650043 Kemerovo, Russia \\ 3 Natural Nutraceutical Biotesting Laboratory, Kemerovo State University, Krasnaya Street 6, \\ 650043 Kemerovo, Russia \\ 4 Department of General Mathematics and Informatics, Kemerovo State University, Krasnaya Street 6, \\ 650043 Kemerovo, Russia \\ 5 Kuzbass State Agricultural Academy, Markovtseva Street 5, 650056 Kemerovo, Russia; elen.ulrich@mail.ru \\ * Correspondence: pavvm2000@mail.ru; Tel.: +7-384-239-6832
}

\section{check for} updates

Citation: Sukhikh, S.; Noskova, S.; Ivanova, S.; Skrypnik, L.; Pungin, A.; Ulrikh, E.; Chupakhin, E.; Babich, O. Study of the Properties of In Vitro Dactylorhiza maculata (L.) Soó (Family Orchidaceae) Extracts. Plants 2021, 10, 1330. https://doi.org/10.3390/ plants10071330

Academic Editors: Laura

Grațiela Vicaș and Mariana

Eugenia Mureșan

Received: 29 May 2021

Accepted: 28 June 2021

Published: 29 June 2021

Publisher's Note: MDPI stays neutral with regard to jurisdictional claims in published maps and institutional affiliations.

Copyright: (C) 2021 by the authors. Licensee MDPI, Basel, Switzerland. This article is an open access article distributed under the terms and conditions of the Creative Commons Attribution (CC BY) license (https:/ / creativecommons.org/licenses/by/ $4.0 /)$.

\begin{abstract}
The medicinal plant Dactylorhiza maculata (L.) Soó (family Orchidaceae) is used to treat gastritis, colic, gastrointestinal tract, and bladder diseases. This study aimed to investigate the properties and characteristics of the in vitro Dactylorhiza maculata extract. The recommended parameters for producing Dactylorhiza maculata extract were determined: temperature $60{ }^{\circ} \mathrm{C}$, process duration $60 \mathrm{~min}$, hydro module 1:10. It is recommended to carry out the extraction using an aqueous ethyl alcohol solution with a mass fraction of the parent substance of $70 \%$. It was found that such biologically active substances as rutin, quercetin, $3,3^{\prime}, 4^{\prime}, 5,5^{\prime}, 7$-hexahydroxyflavonone, 3, 3' $3^{\prime} 4^{\prime}, 5,5^{\prime}, 7-$ hexahydroxyflavonone-3-O-glycoside, gallic acid, and ferulic acid were dominant in Dactylorhiza maculata. A high phosphorus content was noted $(2410.8 \mathrm{mg} / \mathrm{kg}$ dry matter). The studied Dactylorhiza maculata samples contained a large number of organic acids and water-soluble vitamins. The tested extracts were safe in terms of the content of heavy metals, pesticides, aflatoxin B1, and radionuclides, as well as pathogenic and opportunistic microorganisms; the content was significantly lower than the threshold limit values. The studied complex of biologically active substances from Dactylorhiza maculata extract samples had antimicrobial properties. It was found that the antioxidant activity of the samples was $217.89 \pm 10.89 \mathrm{mg} \mathrm{AA} / \mathrm{g}$ (AA—ascorbic acid). The high content of bioactive substances and the antimicrobial and antioxidant properties of Dactylorhiza maculata extract samples determine the application potential of this plant as a substitute for growth stimulants and feed antibiotics in the production of feed additives, aiming to increase the physiological and immune status of livestock and poultry.
\end{abstract}

Keywords: Dactylorhiza maculata; extracts; biologically active substances; toxicological; antimicrobial properties; antioxidant activity

\section{Introduction}

Gastrointestinal diseases from various causes present a considerable problem for the livestock industry, as they lead to low productivity and the death of young animals [1]. Some of the factors or reasons for dysfunctions of the gastrointestinal system are closely connected to aspects of industrial livestock production, and include the stresses associated with veterinary treatments, housing, and feeding conditions, including the quality of feed [2].

Among the many medicines used to preserve the livestock and treat diseases of the gastrointestinal tract, course and feed antibiotics are most often used; however, their 
prolonged and unconsidered use reduces the body's resistance to fungal and staphylococcal infections, and disrupts the processes of digestion and metabolism, as a result of which it decreases live weight gain and the quality of livestock products, including the fact that meat raw materials may contain residual amounts of antibiotic agents [3]. In addition, pathogens tend to acquire resistance to frequently and long-used antibiotics, leading to the ineffectiveness of their use [4].

Currently, the number of studies on the use of medicinal plants in the treatment and prevention of a wide range of diseases in humans and animals has increased worldwide [5], including the development of feed additives, biologically active substances (BAS), that can replace antibiotics. This has to do with the fact that despite the effectiveness of antibiotics in treating and preventing livestock health problems, they also contribute to the development of adaptation to them in pathogenic microorganisms [6].

The use of plant components as feed additives that can increase livestock productivity, stimulate reproduction, and improve the consumer properties of products is relevant and promising. Such components of the livestock diet, called "phytogenic feed additives" (phytogenics), have been widely used since the year 2000, primarily in pig and poultry farming. Interest in them is associated with the restriction on using certain synthetic growth promoters (antibiotic growth promoters) in EU countries [7]. The main reason for these limitations is the desire to improve the quality of products, and minimize the risk of developing resistance to pathogenic microorganisms both in animals and humans as the final consumers [8].

The main effects of phytogenics are increased food intake, stimulation of digestion and growth, reduced incidence of diarrhea, improved feed efficiency and productivity, and ultimately increased production profitability (Commission implementation regulation (EC) No. 131/2012).

The search for new effective phytogenic additives is a promising and relevant area of animal husbandry, especially considering modern international requirements for product safety [9].

A promising raw material for the production of biologically active substances of antimicrobial action from which to create feed additives is medicinal plants, such as Cotinus coggygria, Lunaria rediviva, Sarothamnus scoparius, Eryngium maritimum, Goodyera repens, Corallorhiza trifida, Listera cordata, Dactylorhiza maculata, Platanthera chlorantha, P. bifolia, etc., of the Kaliningrad region, which is characterized by a mild climate and landscape diversity. [10].

Many plants of the Orchidaceae genus are used in traditional medicine. Their chemical components and pharmacology have been studied for the past 15 years. Dactylorhiza maculata has not undergone detailed pharmacological studies. A wide range of chemical compounds has been identified in this plant, including alkaloids, bibenzyl derivatives, flavonoids, phenanthrenes, and terpenoids, which have recently been isolated from this species. These plants' extracts and metabolites, especially those obtained from flowers and leaves, have valuable pharmacological properties. Their diuretic, antirheumatic, antiinflammatory, anticarcinogenic, hypoglycemic, antimicrobial, anticonvulsant, relaxing, neuroprotective, and antiviral effects are particularly interesting [11,12].

It is known that Dactylorhiza maculata is mainly found in the northern and central regions of the non-chernozem zone. The biomass of the medicinal plant contains mainly rutin, quercetin, ferulic acid, hexahydroxyflavonone, and gallic acid. In addition, the composition of the medicinal plant includes essential oils and bitter substances $[13,14]$. This medicinal plant is used for gastritis, gastrointestinal tract diseases, colic, and a strengthening agent for gastrointestinal tract motility and bladder diseases. Dactylorhiza maculata is used as a general tonic in folk medicine, and has anti-inflammatory and enveloping properties [14].

Over the past decades, increased anthropogenic activity, rapid industrialization, and modern agricultural practices have led to increased environmental pollution with heavy metals, which has increased the toxicity of plants, including non-endemic ones. Large areas of land are already contaminated with heavy metals due to the use of pesticides, 
fertilizers, household and compost waste, as well as due to the emissions of heavy metals by metallurgical facilities, and mines containing metals. Although many heavy metals are found naturally in the Earth's crust at various levels, the problem arises when they are released into the environment in excess by natural and/or anthropogenic activities and, through the air and water, enter and accumulate in plants [15].

This study aimed to investigate the properties and characteristics of the in vitro Dactylorhiza maculata extract (chemical composition, content of biologically active substances, content of heavy metals, toxicological properties, antimicrobial and antioxidant activity). For the first time, rational values of the parameters of the BAS isolation process from Dactylorhiza maculata, which is widespread in the territory of the Russian region of the Baltics, were determined. The content of heavy metals and toxicological properties were determined, and the antimicrobial and antioxidant activities of the Dactylorhiza maculata extracts were proved; the obtained data allowed the consideration of Dactylorhiza maculata as a possible part of feed additive formulations aiming to increase the physiological and immune status of livestock and poultry.

\section{Results}

In this study, the conditions for the production process of Dactylorhiza maculata extracts enriched with BAS were selected. The extraction temperature, duration, and hydro module (the quantitative ratio of organic solvent and plant raw materials) were chosen as the primary technological parameters that affect the yield of the plant extract of biologically active substances [14].

\subsection{Optimization of BAS Extraction Parameters}

At the preliminary stage of the study, the possibility of using different solvents (methanol, acetone, isopropyl alcohol, and ethanol) at different concentrations to obtain Dactylorhiza maculata extracts was considered. It was found that the highest extract yield is obtained when using ethanol with a concentration of $70 \%$. The results of optimizing the technological parameters for producing a Dactylorhiza maculata extract enriched with BAS using 70\% ethanol as an extractant are presented in Tables 1 and 2.

Table 1. Dependence of the yield of the Dactylorhiza maculata extract on the hydro module at different durations of the process (temperature $60^{\circ} \mathrm{C}$ ).

\begin{tabular}{ccccccc}
\hline \multirow{2}{*}{$\begin{array}{c}\text { Hydro } \\
\text { Module }\end{array}$} & \multicolumn{5}{c}{ Extract Yield (\%) at the Different Duration of the Extraction Process, Min } \\
\cline { 2 - 7 } & $\mathbf{1 0}$ & $\mathbf{3 0}$ & $\mathbf{6 0}$ & $\mathbf{1 2 0}$ & $\mathbf{1 8 0}$ \\
\hline $1: 1$ & $1.15 \pm 0.03^{\mathrm{a} / \mathrm{a}}$ & $2.14 \pm 0.06^{\mathrm{a} / \mathrm{b}}$ & $6.66 \pm 0.19^{\mathrm{a} / \mathrm{c}}$ & $6.92 \pm 0.20^{\mathrm{a} / \mathrm{c}}$ & $7.15 \pm 0.21^{\mathrm{a} / \mathrm{c}}$ & $7.90 \pm 0.23^{\mathrm{a} / \mathrm{c}}$ \\
$1: 2$ & $1.93 \pm 0.05^{\mathrm{ab} / \mathrm{a}}$ & $2.57 \pm 0.07^{\mathrm{ab} / \mathrm{a}}$ & $7.19 \pm 0.21^{\mathrm{a} / \mathrm{b}}$ & $7.81 \pm 0.23^{\mathrm{a} / \mathrm{b}}$ & $8.12 \pm 0.24^{\mathrm{ab} / \mathrm{bc}}$ & $8.71 \pm 0.26^{\mathrm{ab} / \mathrm{c}}$ \\
$1: 5$ & $2.28 \pm 0.06^{\mathrm{b} / \mathrm{a}}$ & $3.12 \pm 0.09^{\mathrm{b} / \mathrm{a}}$ & $8.72 \pm 0.26^{\mathrm{b} / \mathrm{b}}$ & $8.86 \pm 0.26^{\mathrm{b} / \mathrm{b}}$ & $8.92 \pm 0.26^{\mathrm{b} / \mathrm{b}}$ & $9.02 \pm 0.27^{\mathrm{b} / \mathrm{b}}$ \\
$1: 10$ & $2.82 \pm 0.08^{\mathrm{bc} / \mathrm{a}}$ & $4.71 \pm 0.14^{\mathrm{c} / \mathrm{b}}$ & $9.07 \pm 0.27^{\mathrm{b} / \mathrm{c}}$ & $9.05 \pm 0.26^{\mathrm{b} / \mathrm{c}}$ & $9.03 \pm 0.27^{\mathrm{b} / \mathrm{c}}$ & $9.01 \pm 0.27^{\mathrm{b} / \mathrm{c}}$ \\
$1: 20$ & $3.07 \pm 0.09^{\mathrm{c} / \mathrm{a}}$ & $4.84 \pm 0.14^{\mathrm{c} / \mathrm{b}}$ & $9.15 \pm 0.27^{\mathrm{b} / \mathrm{c}}$ & $9.10 \pm 0.27^{\mathrm{b} / \mathrm{c}}$ & $9.03 \pm 0.27^{\mathrm{b} / \mathrm{c}}$ & $9.02 \pm 0.27^{\mathrm{b} / \mathrm{c}}$ \\
\hline
\end{tabular}

Data presented as a mean $\pm \mathrm{SD}(n=3)$. Values in columns/rows followed by the same letter do not differ significantly $(p>0.05)$, as assessed by the post hoc test (Tukey test).

Table 2. Dependence of the Dactylorhiza maculata extract yield on temperature for different durations of the process (hydro module 1:10).

\begin{tabular}{|c|c|c|c|c|c|c|}
\hline \multirow{2}{*}{$\begin{array}{c}\text { Temperature, } \\
{ }^{\circ} \mathrm{C}\end{array}$} & \multicolumn{6}{|c|}{ Extract Yield (\%) at the Different Duration of the Extraction Process, Min } \\
\hline & 10 & 30 & 60 & 120 & 180 & 360 \\
\hline 25 & $1.66 \pm 0.05^{a / a}$ & $3.83 \pm 0.11^{\mathrm{a} / \mathrm{b}}$ & $9.12 \pm 0.27 \mathrm{a} / \mathrm{c}$ & $9.24 \pm 0.27^{\mathrm{a} / \mathrm{c}}$ & $9.82 \pm 0.29$ a/c & $9.91 \pm 0.29^{a / c}$ \\
\hline 40 & $2.21 \pm 0.06^{\mathrm{a} / \mathrm{a}}$ & $5.99 \pm 0.18^{\mathrm{b} / \mathrm{b}}$ & $10.04 \pm 0.30 \mathrm{ab} / \mathrm{c}$ & $10.02 \pm 0.30 \mathrm{ab} / \mathrm{c}$ & $10.02 \pm 0.30 \mathrm{ab} / \mathrm{c}$ & $10.05 \pm 0.30 \mathrm{ab} / \mathrm{c}$ \\
\hline 60 & $3.24 \pm 0.09 \mathrm{~b} / \mathrm{a}$ & $6.47 \pm 0.19^{b / b}$ & $10.75 \pm 0.32 \mathrm{~b} / \mathrm{c}$ & $10.71 \pm 0.32^{b / c}$ & $10.75 \pm 0.32 \mathrm{~b} / \mathrm{c}$ & $10.74 \pm 0.32^{b / c}$ \\
\hline 70 & $4.07 \pm 0.12^{\mathrm{c} / \mathrm{a}}$ & $6.98 \pm 0.21^{\mathrm{b} / \mathrm{b}}$ & $10.68 \pm 0.32 \mathrm{~b} / \mathrm{c}$ & $10.63 \pm 0.32 \mathrm{~b} / \mathrm{c}$ & $10.59 \pm 0.32 \mathrm{~b} / \mathrm{c}$ & $10.14 \pm 0.32 \mathrm{~b} / \mathrm{c}$ \\
\hline Boiling & $4.19 \pm 0.12^{\mathrm{c} / \mathrm{a}}$ & $6.96 \pm 0.20^{\mathrm{b} / \mathrm{b}}$ & $10.57 \pm 0.32^{\mathrm{b} / \mathrm{c}}$ & $10.48 \pm 0.31^{b / c}$ & $10.33 \pm 0.32^{b / c}$ & $10.20 \pm 0.32^{b / c}$ \\
\hline
\end{tabular}

Data presented as a mean $\pm \mathrm{SD}(n=3)$. Values in columns/rows followed by the same letter do not differ significantly $(p>0.05)$, as assessed by the post hoc test (Tukey test). 


\subsection{Isolation of BAS from Extracts}

Preparative chromatography was used to isolate individual compounds from the mixture in the pure form [15]. The results of isolating individual biologically active substances from Dactylorhiza maculata extract samples by preparative chromatography are shown in Figures 1-4.

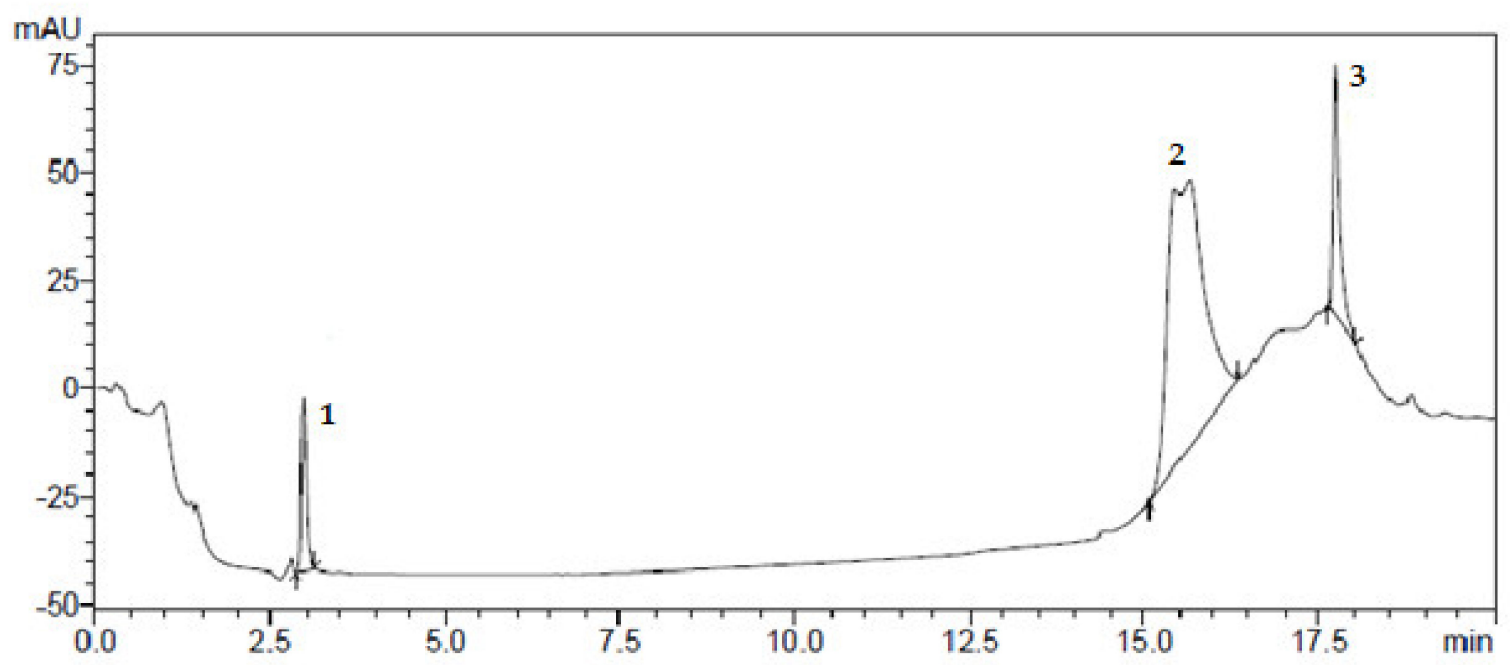

Figure 1. Preparative isolation of BAS from Dactylorhiza maculata extract samples: (1) rutin; (2) hyperoside; (3) ferulic acid.

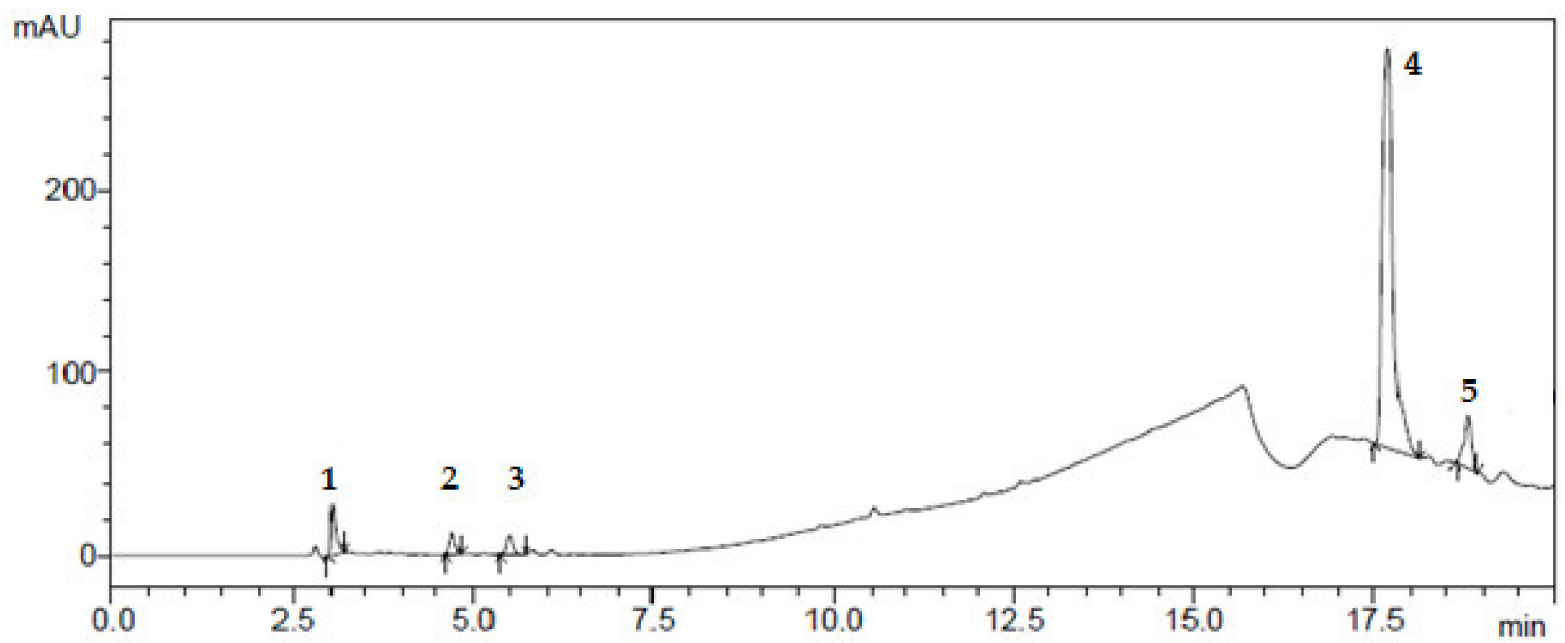

Figure 2. Preparative isolation of BAS from Dactylorhiza maculata extract samples: (1) disulforetin; (2) sulfuretin; (3) sulfurein; (4) quercetin; (5) kaempferol. 


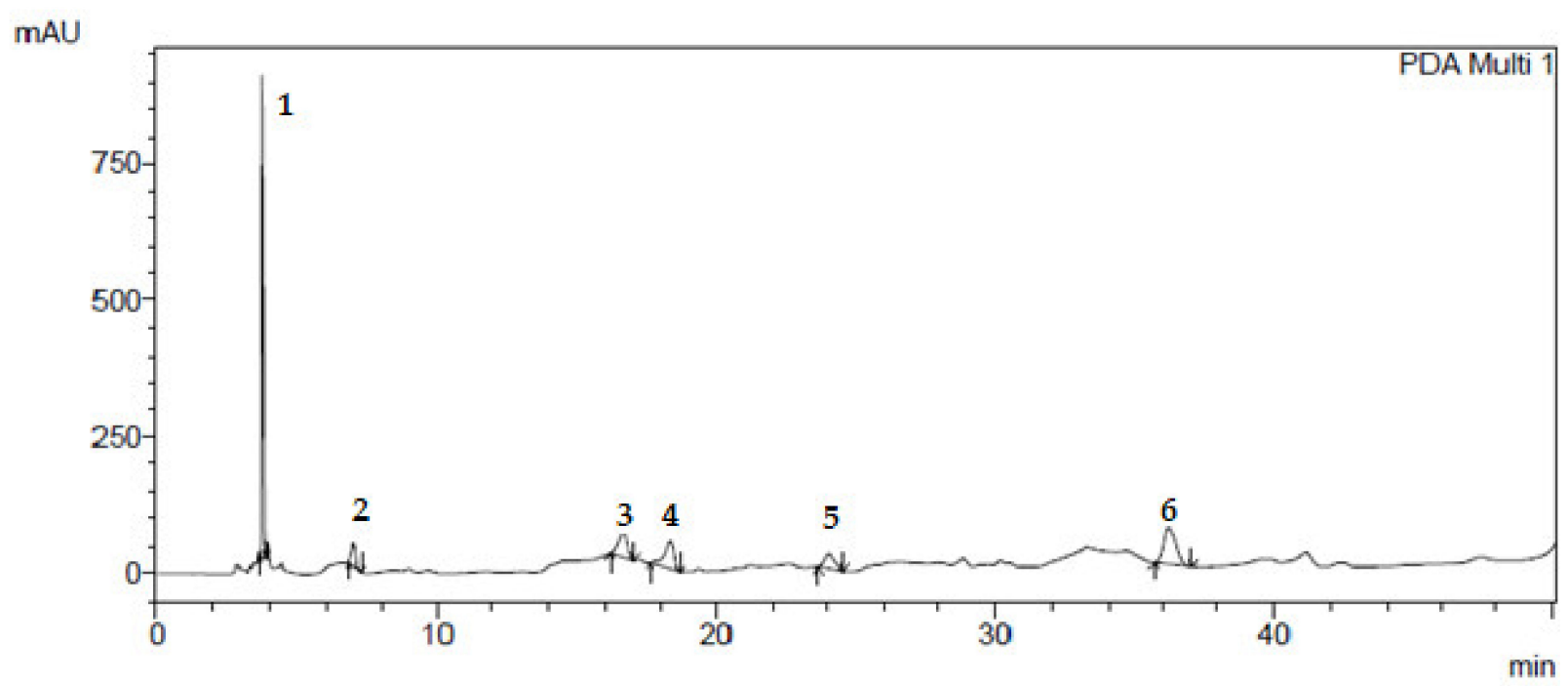

Figure 3. Isolation of hydroxyflavones from Dactylorhiza maculata extract samples by preparative chromatography: (1) apigenin; (2) 7,8-dihydroxyflavone; (3) 3-hydroxyflavone; (4) 5-hydroxyflavone; (5) luteolin; (6) luteolin 3,4'-diglucoside.

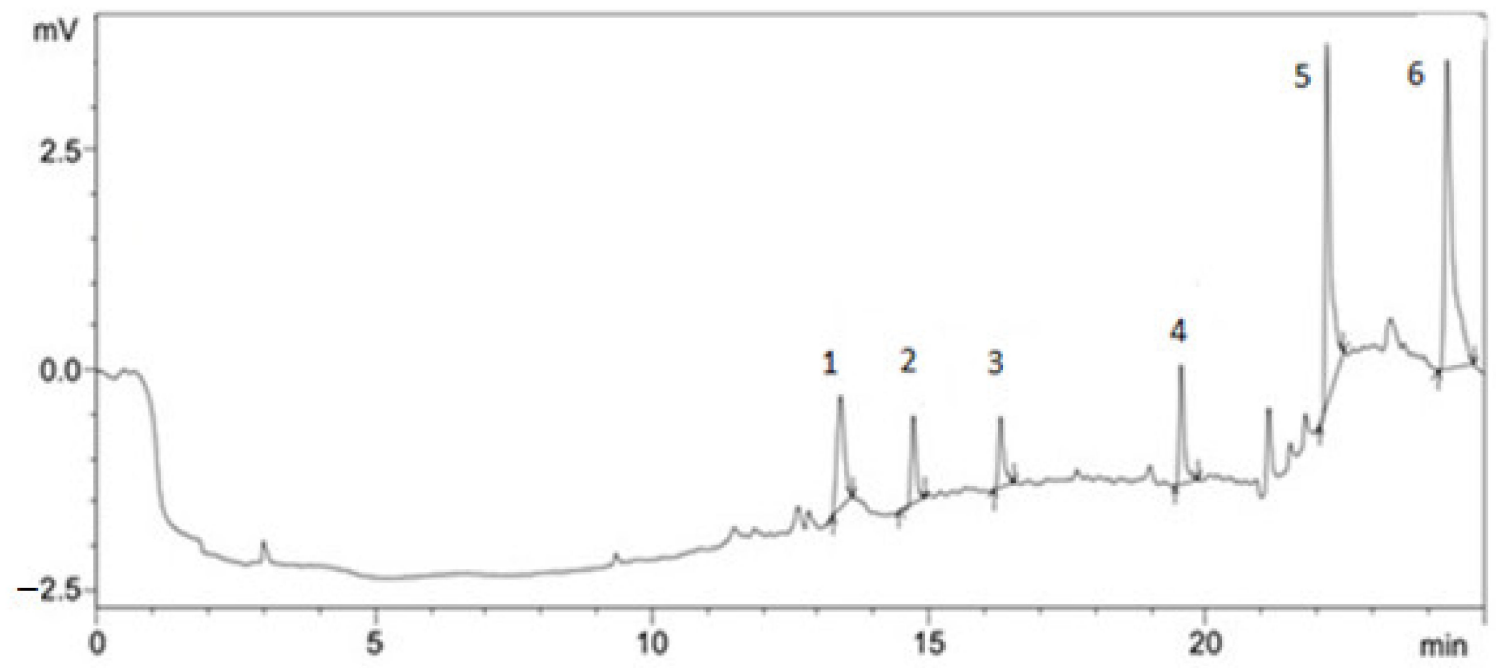

Figure 4. BAS isolated from Dactylorhiza maculata extract samples by HPLC: (1) 3,3' ,4',5,5',7-hexahydroxyflavonone; (2) $3,3^{\prime}, 4^{\prime}, 5,5^{\prime}, 7$-hexahydroxyflavonone-3-O-glycoside; (3) gallic acid; (4) ferulic acid; (5) rutin; (6) quercetin.

The results of determining the qualitative and quantitative composition of BAS from Dactylorhiza maculata extracts are presented in Table 3.

Table 3. The results of the quantitative determination of individual BAS from the Dactylorhiza maculata extract.

\begin{tabular}{lc}
\hline BAS & Content, $\mathbf{~ g / 1 0 0 ~} \mathbf{g}$ \\
\hline Rutin & $8.52 \pm 0.25$ \\
Quercetin & $11.07 \pm 0.33$ \\
$3,3^{\prime}, 4^{\prime}, 5,5^{\prime}, 7$-hexahydroxyflavonone & $12.58 \pm 0.37$ \\
$3,3^{\prime} 4^{\prime}, 5,5^{\prime}, 7$-hexahydroxyflavonone-3-O- & $13.04 \pm 0.39$ \\
glycoside & $35.92 \pm 1.07$ \\
Gallic acid & $24.09 \pm 0.72$ \\
Ferulic acid & \\
\hline BAS: biologically active substances. Data presented as a mean \pm SD $(n=3)$.
\end{tabular}




\subsection{Determination of the Antimicrobial Activity of Extracts}

The results of evaluating the antimicrobial activity of Dactylorhiza maculata extracts are presented in Table 4.

Table 4. The results of evaluating the antimicrobial activity of Dactylorhiza maculata extracts.

\begin{tabular}{cccccc}
\hline \multirow{2}{*}{ Samples } & \multicolumn{5}{c}{ Lysis Zone Diameter, Mm } \\
\cline { 2 - 6 } & E. coli & S. aureus & P. vulgaris & C. albicans & L. mesenteroides \\
\hline Extract & $17.0 \pm 0.5$ & $15.0 \pm 0.5$ & $14.0 \pm 0.5$ & $15.0 \pm 0.5$ & $17.0 \pm 0.5$ \\
Control & $3.0 \pm 0.1$ & $2.0 \pm 0.1$ & $2.0 \pm 0.1$ & $3.0 \pm 0.1$ & $4.0 \pm 0.2$ \\
Rifampicin & $23.0 \pm 0.5$ & $21.0 \pm 0.5$ & $20.0 \pm 0.5$ & $19.5 \pm 0.5$ & $18.0 \pm 0.5$ \\
\hline
\end{tabular}

Control: tannin solution 1\%. Data presented as a mean \pm SD $(n=3)$.

The studied Dactylorhiza maculata extract samples had antimicrobial properties against the tested strains (Escherichia coli, Staphylococcus aureus, Proteus vulgaris, Candida albicans, Leuconostoc. mesenteroides).

\subsection{Determination of Toxicological Parameters of Extracts}

The content of toxic elements is presented in Table 5.

Table 5. The content of toxic elements in Dactylorhiza maculata extracts.

\begin{tabular}{cc}
\hline Component & Content, $\mathbf{~ g / k g}$ \\
\hline Mercury & $>0.0001$ \\
Cadmium & $>0.002$ \\
Lead & $>0.002$ \\
Arsenic & $>0.08$ \\
Copper & 0.7 \\
Zinc & 0.9 \\
The sum of the $\alpha$-, $\beta$ - and $\gamma$-isomers of hexachlorocyclohexane & $>0.001$ \\
1,1,1-trichloro-2,2-bis(4-chlorophenyl)ethane & $>0.007$ \\
Aflatoxin B1 & 0.005 \\
Strontium-90 & 2.0 \\
Cesium-137 & 1.9 \\
\hline
\end{tabular}

Data presented as a mean $\pm \operatorname{SD}(n=3)$.

The content of heavy metals, pesticides, aflatoxin B1, and radionuclides in the Dactylorhiza maculata BAS complex extract samples was within the acceptable limits $[12,16]$.

\subsection{Determination of the Antioxidant Activity of Extracts}

The antioxidant activity of the Dactylorhiza maculata extract samples was $217.89 \pm 10.89 \mathrm{mg} \mathrm{AA} / \mathrm{g}$, which indicates the high antioxidant characteristics of the obtained extracts.

\subsection{Determination of Microbiological Parameters of Extracts}

The results of studying the microbiological safety indicators of the obtained Dactylorhiza maculata BAS complex extract samples showed their high microbiological reliability (coliform bacteria, toxin-forming anaerobes, pathogenic microorganisms, including $L$. monocytogenes, Salmonella, and St. aureus were not found).

\section{Discussion}

The extraction process was carried out at different temperatures for a duration from $10 \mathrm{~min}$ to $360 \mathrm{~min}$ (Tables 1 and 2). No statistically significant differences $(p<0.05)$ were found in the yield of the extract, with an extraction duration of at least $60 \mathrm{~min}$. With this extraction duration ( $\geq 60 \mathrm{~min}$ ), no statistically significant differences were found at the ratio of the hydro module at 1:1, 1:2 and 1:5, 1:10, 1:20, but significant differences were established 
between 1:(2 maximum) and 1:(5 minimum). A statistically significant difference was found at an extraction temperature up to $40{ }^{\circ} \mathrm{C}$ and not less than $60{ }^{\circ} \mathrm{C}(p=0.879-0.921)$. The recommended parameters for producing a plant extract from Dactylorhiza maculata were a temperature of $60^{\circ} \mathrm{C}$, a process duration of $60 \mathrm{~min}$, and a hydro-module of 1:10. The yield of the plant extract, in this case, was $9.07 \%$. Under these conditions, the extraction of biologically active substances was the most complete (the extraction process was carried out with an aqueous solution of ethyl alcohol with a mass fraction of the active substance of $70 \%$ ) [16].

Rutin, quercetin, 3,3' , $4^{\prime}, 5,5^{\prime}, 7$-hexahydroxyflavonone-3-O-glycoside, gallic acid, and ferulic acid were isolated from fractions of Dactylorhiza maculata extract in the system with methylene chloride:methanol at 4:1 by preparative HPLC. HPLC was carried out using a column with phenyl end-capping and modified with nitrile and octyl groups, sorbent size $2.5 \mu \mathrm{m}$, pores $25 \mathrm{~nm}$, inner diameter $2.5 \mathrm{~mm}$, length $150 \mathrm{~mm}$. The eluent was composed of phosphate buffer ( $\mathrm{pH} 8.8$ ) and 30\% acetonitrile, with a flow rate of $1 \mathrm{~mL} / \mathrm{min}$, and a chromatography time of $30 \mathrm{~min}$. The collection of individual substances was carried out automatically using a fraction collector [17].

The Dactylorhiza maculata extract (Table 3) showed high concentrations of gallic $(35.92 \mathrm{mg} / 100 \mathrm{~g})$ and ferulic $(24.09 \mathrm{mg} / 100 \mathrm{~g})$ acids. The extract of this plant also contained significant amounts of such flavonoids as $3,3^{\prime}, 4^{\prime}, 5,5^{\prime}, 7$-hexahydroxyflavonone-3-Oglycoside (13.04 mg/100 g), 3,3', $4^{\prime}, 5,5^{\prime}, 7$-hexahydroxyflavonone (12.58 mg/100 g), quercetin $(11.07 \mathrm{mg} / 100 \mathrm{~g})$ and rutin $(8.52 \mathrm{mg} / 100 \mathrm{~g})$.

When comparing the BAS of the Dactylorhiza maculata growing on the Kaliningrad region and the Belarus territory, it was found that in vitro Dactylorhiza maculata of the Kaliningrad region contains 13\% more flavonoids than the Belarusian one [18].

As Dactylorhiza maculata extracts are planned to be used for producing feed additives for livestock, studying their toxicological and microbiological safety indicators was of interest [19]. It is known that the toxicological indicators of plant raw materials and extracts of the BAS complex isolated from medicinal plants are not constant and depend on the composition of the soil and the ecological situation of the growing region. Microbiological indicators of the feedstock intended for the production of feed additives for livestock are also not constant and depend on the sanitary and hygienic state of production facilities. In this regard, the toxicological and microbiological indicators of the safety of herbal extracts should be regularly studied. The main toxicological indicators were the contents of mercury, cadmium, lead, arsenic, copper, zinc, as well as the contents of aflatoxin B1, pesticides, and radionuclides.

Empirical data obtained in the course of studying the quantitative content of heavy metals, in plant extracts of the BAS complex from Dactylorhiza maculata, show that these extracts have a low content of such metals as mercury, cadmium, lead, and arsenic.

Thus, mercury content in the studied samples of plant extracts of the BAS complex isolated from Dactylorhiza maculata did not exceed $0.0001 \mathrm{mg} / \mathrm{kg}$. The cadmium and lead content were within the normal range and was less than $0.002 \mathrm{mg} / \mathrm{kg}$ for each indicator. It was experimentally established that the arsenic content in plant extracts did not exceed $0.08 \mathrm{mg} / \mathrm{kg}$.

The BAS complex extracts isolated from Dactylorhiza maculata contained copper and zinc compounds, but all indicators were within the normal range. The sum of $\alpha_{-}^{-}, \beta-$, and $\gamma^{-}$ isomers of hexachlorocyclohexane in the samples under study did not exceed $0.001 \mathrm{mg} / \mathrm{kg}$, and the content of 1,1,1-trichloro-2,2-bis(4-chlorophenyl)ethane and its metabolites did not exceed $0.007 \mathrm{mg} / \mathrm{kg}$. It was also shown that the studied plant extracts of the BAS complex were within the normal range in terms of the content of aflatoxin B1 and radionuclides. Dactylorhiza maculata extracts were distinguished by high microbiological reliability (coliform bacteria in $0.01 \mathrm{~g}$, toxin-forming anaerobes in $1.0 \mathrm{~g}$, pathogenic microorganisms, including L. monocytogenes and bacteria of the genus Salmonella in $25.0 \mathrm{~g}$, St. aureus in $1.0 \mathrm{~g}$-were not detected). 
The Table 4 data indicate that the studied Dactylorhiza maculata extracts had antimicrobial properties against the tested strains (Escherichia coli, Staphylococcus aureus, Proteus vulgaris, Candida albicans, Leuconostoc mesenteroides).

The antioxidant activity of the Dactylorhiza maculata extract samples obtained in the territory of central Russia was $217.89 \pm 10.89 \mathrm{mg} \mathrm{AA} / \mathrm{g}$, which indicates their high antioxidant properties.

Our results were checked against the results of studying the properties of Dactylorhiza maculata growing in Romania [20]. The research data show that the D. maculata ethanol extract (ethanol content 70\%) contained the highest amount of isoquercitrin $(518.6 \pm 3.7 \mu \mathrm{g} / \mathrm{g})$, followed by quercitrin $(474.6 \pm 4.34 \mu \mathrm{g} / \mathrm{g})$. Ferulic acid, para-coumaric acid, caffeic acid, and kaempferol were also identified, but at a lower concentration $(51.4 \pm 0.45 \mu \mathrm{g} / \mathrm{g}, 69 \pm 0.54 \mu \mathrm{g} / \mathrm{g}, 16.56 \pm 0.12 \mu \mathrm{g} / \mathrm{g}$, and $3.6 \pm 0.22 \mu \mathrm{g} / \mathrm{g}$, respectively. At the same time, in contrast to our extract samples, such compounds as gallic acid and such flavonoids as $3,3^{\prime}, 4^{\prime}, 5,5^{\prime}, 7$-hexahydroxyflavonone-3-O-glycoside, $3,3^{\prime}, 4^{\prime}, 5,5^{\prime}, 7-$ hexahydroxyflavonone, and rutin were not found. The obtained data indicate that the flavonoid composition of Dactylorhiza maculata growing in the Russian Baltic region is much more diverse than the composition of intact Dactylorhiza maculata growing in Romania, containing a large set of polyphenolic compounds. The antioxidant activity presented in the studies [20] was $88.87 \pm 0.9 \mathrm{mg} \mathrm{AA} / \mathrm{g}$, while the antioxidant activity of our Dactylorhiza maculata extract samples is 2.5 times higher. The plant components that prevent the accumulation of oxidants in Dactylorhiza maculata, which we collected, are represented by flavonoids and phenolic compounds, while in studies [20], antioxidants are represented mainly by polyphenols and vitamins $C, E$, and $\beta$-carotene. These facts can be explained by favorable microclimate conditions with a sufficient amount of nutrients in the soil. The obtained data determine the prospects for the use of in vitro Dactylorhiza maculata BAS as feed additives.

In the study of the antimicrobial activity of Dactylorhiza maculata extracts, presented in [20], it was found that the results of determining the lysis zone are in good agreement with our data. In our studies and in [20], antimicrobial activity was found against the same pathogenic and opportunistic microorganisms: E. coli, S. aureus, P. vulgaris, C. albicans, and L. mesenteroides.

The presence of antioxidant activity was proved by significant results that correlate with the contents of antioxidants (polyphenolic compounds) in Dactylorhiza maculata, growing in the territory of the Russian region of the Baltics. All these results represent essential criteria for the identification and characterization of biologically active substances. In addition, these studies offer new opportunities for further studies of bioactive compounds of in vitro D. maculata species.

The results of these studies indicate the safety of the obtained samples of the Dactylorhiza maculata extract from a toxicological and microbiological point of view, which makes it possible to recommend their use as ingredients in the formulation of feed additives for livestock [21].

\section{Materials and Methods}

\subsection{Research Objects}

Samples of Dactylorhiza maculata (L.) Soó (family Orchidaceae) extract were used as objects of research. The raw material for the extracts was the medicinal plant Dactylorhiza maculata, collected in August 2020 in the Kaliningrad region. The biomaterial of the species was confirmed by A. Pungin, the head of the herbarium of the Institute of Living Systems of the IKBFU (protocol No. 16/2020). The aerial parts of mature plants (shoots, leaves, and flowers) were collected. The ratio of shoots/leaves/flowers in the harvested biomass was, on average, 4:2:1 for each medicinal plant. Extracts were produced from the collected biomaterial of the medicinal plant. 


\subsection{Study of the Chemical Composition of Plant Extracts}

HPLC method (Shimadzu LC-20AD chromatograph, Kyoto, Japan) according to GPM.1.2.1.2.0005.15 (high-performance liquid chromatography: general pharmacopeia monograph) was applied to study the chemical composition of Dactylorhiza maculata extracts; detection was carried out using a diode array detector in the range detection of $180 \mathrm{~nm}-900 \mathrm{~nm}$, the flow rate of the eluent in all cases was $1 \mathrm{~mL} / \mathrm{min}$. The preparative isolation of Dactylorhiza maculata hydroxyflavones was carried out by HPLC, using an amine phase column with phenyl end-capping, sorbent size $2.5 \mu \mathrm{m}$, pores $25 \mathrm{~nm}$, inner diameter $2.5 \mathrm{~mm}$, length $150 \mathrm{~mm}$. The conditions were: eluent phosphate buffer, $\mathrm{pH} 8.8$, $30 \%$ acetonitrile, flow rate $1 \mathrm{~mL} / \mathrm{min}$, chromatography time $60 \mathrm{~min}$. The collection of individual substances was carried out automatically using a fraction collector [3].

$3,3^{\prime}, 4^{\prime}, 5,5^{\prime}, 7$-hexahydroxyflavonone ( $\left.\geq 95.0 \%, 42866\right), 3,3^{\prime}, 4^{\prime}, 5,5^{\prime}, 7$-hexahydroxyflavonone3-O-glycoside (certified reference material, CAS:153-18-4), 3-hydroxyflavone ( $\geq 98 \%$, H4280), 5-hydroxyflavone ( $\geq 90 \%$, H4405), 7,8-dihydroxyflavone (certified reference material, CAS:38183-03-8), apigenin ( $\geq 95 \%$, 10798), gallic acid ( $\geq 97.5 \%$, G7384), hyperoside (certified reference material, CAS:482-36-0), disulfuretin (certified reference material, CAS:97-77-8), quercetin $(\geq 95.0 \%$, Q4951), kaempferol $(\geq 97.0 \%, 60010)$, luteolin $(\geq 98 \%$, L9283), ruthin ( $\geq 95.0 \%$, PHL89270), sulfurein (certified reference material, CAS:120-05-8), sulfuretin (certified reference material, CAS: $120-05-8)$, and ferulic acid $(\geq 99 \%, 128708)$ were purchased from Fluka/Sigma-Aldrich (Sigma-Aldrich Rus., Moscow, Russia). The values of the standard samples for BAS were used to construct calibration curves, which were used to determine the number of components.

\subsection{Determination of the Heavy Metal Content in Plant Extracts}

The method for the mercury content determination is based on the destruction of the analyzed sample by a mixture of nitric and sulfuric acids, precipitation of mercury with copper iodide, and subsequent colorimetric determination in the form of copper tetraiodomercuroate, by comparison with a standard scale [16].

The method for determining cadmium is based on the dry mineralization (ashing) of a sample using nitric acid as an auxiliary agent, and quantitative determination of cadmium by polarography in alternating current mode [16].

The method for arsenic determination is based on measuring the color intensity of a solution of a complex compound of arsenic with silver diethyldithiocarbamate in chloroform. The method for the determination of copper and zinc is based on the dry mineralization (ashing) of a sample using nitric acid as an auxiliary agent, and quantitative determination of copper (zinc) by polarography, in alternating current mode [2].

\subsection{Study of Toxicological Indicators of Plant Extracts}

The presence of aflatoxin B1 in the Dactylorhiza maculata extract was determined using the enzyme immunoassay [22]. Organochlorine pesticides were determined by gas chromatography with an electron capture detector or a mass selective detector [23]. The presence of radionuclides was determined by measuring the activity of radionuclides using the radiometric method [23].

\subsection{Study of Microbiological Parameters of Plant Extracts}

The method for the determination of mesophilic aerobic and facultative anaerobic microorganisms is based on inoculation of the product and/or dilutions of the weighed product portion into a liquid nutrient medium, the incubation of inoculates, accounting for visible signs of microorganism growth, if necessary, the subculture of culture liquid on agar nutrient media to confirm the growth of microorganisms, and finally, counting their numbers using the table. Coliform bacteria are determined by inoculation on agar selective diagnostic media; toxin-forming anaerobes are determined by inoculating a certain amount of the product or its dilutions into a liquid selective medium, isolating characteristic colonies and confirming their attribution using biochemical tests. Pathogenic 
microorganisms of the genus Listeria are determined by inoculation on a selective medium and the presence of colonial growth with growth characteristics. S. aureus was detected and quantified by inoculation on agar selective diagnostic media, counting the number of characteristic colonies (when determining the $S$. aureus number), confirming the attribution of the isolated characteristic colonies to $S$. aureus by biochemical signs [24].

\subsection{Determination of the Antimicrobial Activity of Plant Extracts}

Antimicrobial activity of the in vitro Dactylorhiza maculata extract samples against the growth of opportunistic and pathogenic test strains was determined by two methods: the diffusion method (on a solid nutrient medium) and a method based on measuring the optical density (in a liquid nutrient medium) [2]. Medical and natural test strains were used as opportunistic and pathogenic microorganisms (Escherichia coli ATCC 25922, Staphylococcus aureus ATCC 25923, Proteus vulgaris ATCC 63, Candida albicans EMTK 34, Leuconostoc mesenteroides EMTK 1865), acquired from the State Collection of Pathogenic Microorganisms and Cell Cultures (GKPM-Obolensk, Obolensk, Russia).

The bacterial lawns of test strains were produced on agar nutrient media, and simultaneously, BAS complex extract samples were placed on the lawn. A paper disc with a nutrient medium was used as a control, and a disc with antibiotic rifampicin (from a standard kit) was used as a reference drug. Petri dishes were incubated at a temperature corresponding to the optimal growth temperature of each test strain for $24 \pm 0.5 \mathrm{~h}$. The results were accounted by the presence and size (in $\mathrm{mm}$ ) of the transparent zone showing the absence of microorganism growth around the disc [3].

All standard media were purchased from Khimreaktivsnab, Ufa, Russia.

\subsection{Determination of the Antioxidant Activity of Plant Extracts}

The antioxidant activity of plant extracts was determined by their ability to reduce the 2,2-diphenyl-1-picrylhydrazyl radical ( $\mathrm{DPPH}, \mathrm{C}_{18} \mathrm{H}_{12} \mathrm{~N}_{5} \mathrm{O}_{6}, \mathrm{M}=394.33$ ). The reaction of the interaction of antioxidants with the DPPH radical proceeds according to the scheme [15]:

$$
\mathrm{DPPH}^{*}+\mathrm{AH} \rightarrow \mathrm{DPPH}-\mathrm{H}+\mathrm{A} \text { * }
$$

As a result of the DPPH radical reduction by an antioxidant, the purple-blue color of $\mathrm{DPPH}$ in ethanol decreases, and the reaction is monitored by the change in optical density using conventional spectrophotometric methods.

All chemicals (analytical or higher grade) used in this study were purchased from Fluka/Sigma-Aldrich (Sigma-Aldrich Rus., Moscow, Russia).

\subsection{Statistical Analysis}

Each experiment was repeated three times, and the data are expressed as means \pm standard deviation. Data processing was carried out via the standard methods of mathematical statistics. Post hoc analysis (Tukey test) was undertaken to identify samples that were significantly different from each other. The equality of the variances of the extracted samples was checked using the Levene test. The data were subjected to analysis of variance (ANOVA) using Statistica 10.0 (StatSoft Inc., 2007, Tusla, OK, USA). Differences between means were considered significant when the confidence interval was below $5 \%$ $(p<0.05)$.

\section{Conclusions}

The chemical composition of the medicinal plant Dactylorhiza maculata, growing in the Kaliningrad region, has been studied. As the result of these studies, the chemical composition, the BAS content, the content of heavy metals, toxicological properties, the antimicrobial and antioxidant activity of the in vitro plant Dactylorhiza maculata were screened for the first time. It was found that the number of flavonoids in in vitro Dactylorhiza maculata is not inferior to the number of flavonoids in a plant [12]. The studied Dactylorhiza maculata samples have demonstrated a broad applicability potential, with the optimal 
combination of antimicrobial and antioxidant activities and the content of a significant amount of essential biologically active substances.

Plant-based feed additives are now widely used to treat and prevent many diseases of livestock and poultry. A limiting factor in introducing domestic medicinal plants into the production of feed additives is the lack of information on the chemical composition of medicinal plant raw materials, and poor knowledge of the medicinal properties of plant preparations [25]. The use of medicinal plants (such as Rhaponticum carthamoides, Echinacea purpurea, Cotinus coggygria, Eryngium maritimum, Dactylorhiza maculata, Platanthera chlorantha, and many others containing similar antimicrobial and antioxidant components) for the production of feed additives is relevant to improving regional economies and improving the quality of life and the nation's health, by providing ecologically clean livestock products. The flavonoids, which are of interest for the production of feed additives for livestock that are an alternative to antibiotics, have been identified among Dactylorhiza maculata BAS.

This study of Dactylorhiza maculata properties offers new opportunities for further research aimed at developing technologies for obtaining plant material in a short time, year-round, regardless of weather conditions; the possibility of producing planting material for species that are difficult to reproduce; reproduction of hybrid forms of plants with preservation of valuable properties; improvement of planting material; the possibility of automating the in vitro reproduction process, and ensuring the genetic homogeneity of the resulting plants.

Author Contributions: Conceptualization and design of the research, O.B., E.C. and S.I.; analysis and interpretation of data, S.S., A.P. and E.C.; contribution of reagents, materials, analysis tools or data, S.N. and E.U.; writing and editing, O.B., L.S. and S.I. All authors have read and agreed to the published version of the manuscript.

Funding: This research was funded by the financial support of the Ministry of Science and Higher Education of the Russian Federation as part of the implementation of the Presidential Grant No. 07515-2021-310 (MD-135.2021.1.4).

Institutional Review Board Statement: Not applicable.

Informed Consent Statement: Not applicable.

Data Availability Statement: Not applicable.

Conflicts of Interest: The authors declare no conflict of interest.

\section{References}

1. Anyanwu, A.A.; Jimam, N.S.; Omale, S.; Wannang, N.N. Antiviral activities of Cucumis metuliferus fruits alkaloids on infectious bursal disease virus (IBDV). J. Phytopharmacol. 2017, 6, 98-101.

2. Babich, O.; Sukhikh, S.; Prosekov, A.; Asyakina, L.; Ivanova, S. Medicinal Plants to Strengthen Immunity during a Pandemic. Pharmaceuticals 2020, 13, 313. [CrossRef]

3. Babich, O.; Sukhikh, S.; Pungin, A.; Ivanova, S.; Asyakina, L.; Prosekov, A. Modern Trends in the In Vitro Production and Use of Callus, Suspension Cells and Root Cultures of Medicinal Plants. Molecules 2020, 25, 5805. [CrossRef] [PubMed]

4. Kirillova, I.A.; Kirillov, D.V.; Shadrin, D.M. Molecular and morphological approaches to studying the Dactylorhiza genus in the Komi Republic. Vestn. Tomsk. Gos. Univ. Biol. 2018, 43, 44-65. [CrossRef]

5. Masondo, N.A.; Staord, G.I.; Aremu, A.O.; Makunga, N.P. Acetylcholinesterase inhibitors from southern African plants: An overview of ethnobotanical, pharmacological potential and phytochemical research including and beyond Alzheimer's disease treatment. S. Afr. J. Bot. 2019, 120, 39-64. [CrossRef]

6. Beeby, E.; Magalhães, M.; Poças, J.; Collins, T.; Lemos, M.F.L.; Barros, L. Secondary metabolites (essential oils) from sand-dune plants induce cytotoxic effects in cancer cells. J. Ethnopharmacol. 2020, 258, 112803. [CrossRef]

7. Alonso, A.; Dominguez, F.; Ruiz, A.J.; Campos, N.; Zapata, J.R.; Carranza, C. Medicinal plants from north and Central America and the Caribbean considered toxic for humans: The other side of the coin. Med. Evid. Based Complement. Altern. Med. 2017, 2017. [CrossRef]

8. Gutiérrez-Grijalva, E.P.; Picos-Salas, M.A.; Leyva-López, N.; Criollo-Mendoza, M.S.; Vazquez-Olivo, G.; Heredia, J.B. Flavonoids and phenolic acids from oregano: Occurrence, biological activity and health benefits. Plants 2018, 7, 2. [CrossRef] 
9. Aborisade, A.B.; Adetutu, A.; Owoade, A.O. Phytochemical and Proximate Analysis of Some Medicinal Leaves. CMR 2017, 6, 209-214. [CrossRef]

10. Radak, B.; Rat, M.; Anačkov, G. Morphological variabillity of populations of the Dactylorhiza maculata (L.) Soó 1962 and D. majalis (Reichenb.) P. F. Hunt et Summerhayes 1965 (Orchidales, Orchidaceae) with Stara planina. Matica Srpska. Zbornik Matice Srpske za Prirodne Nauke 2012, 122, 33-44. [CrossRef]

11. Gutierrez, R. Orchids: A review of uses in traditional medicine, its phytochemistry and pharmacology. J. Med. Plants Res. 2010, 4, 592-638.

12. Nikishina, T.; Kozlova, O.; Levitskaya, G.; Vysotskaya, O. Study of Dactylorhiza Seeds (D. baltica and D. maculata) from the Orchid Collection of the Cryobank at Timiryazev institute of plant physiology Russian Academy of Sciences. Biol. Bull. 2019, 46, 242-250. [CrossRef]

13. Sechin, E.N.; Marakaev, O.A.; Gavrilov, G.B. Amino acid composition of vegetative organs Dactylorhiza maculata (L.) Soó (Orchidaceae). Khimiya Rastit. Syr'ya 2019, 2, 135-143. [CrossRef]

14. Sidorov, A.; Zaytseva, Y.; Marakaev, O. Effect of supernatant of associative bacteria of the genus Pseudomonas on germination, morphogenesis and growth of Dactylorhiza incarnata (L.) Soó (Orchidaceae) in vitro. Vestn. Tomsk. Gos. Univ. Biol. 2020, 51, 6-24. [CrossRef] [PubMed]

15. Fornstedt, T.; Forssén, P.; Samuelsson, J. Modeling of preparative liquid chromatography. In Liquid Chromatography, 2nd ed.; Fanali, S., Haddad, P.R., Poole, C.F., Riekkola, M.-L., Eds.; Elsevier: Amsterdam, The Netherlands, 2017 ; pp. $573-592$.

16. Singh, S.; Parihar, P.; Rachana, S.; Singh, P.; Singh, V.P.; Prasad, S.M. Heavy metal tolerance in plants: Role of transcriptomics, proteomics, metabolomics, and ionomics. Front. Plant. Sci. 2016, 6, 1143. [CrossRef] [PubMed]

17. Djordjevic, S.M. From medicinal plant raw material to herbal remedies. In Aromatic and Medicinal Plants; El-Shemy, H., Ed.; IntechOpun: London, UK, 2017. [CrossRef]

18. Bedulenko, M.A. Soderzhanie efirnogo masla Monarda fistulosa L., inducirovannogo v usloviayh centralnogo botanichskogo sada NAN Belarusi [The content of Monarda fistulosa L. essential oil, introduced in the conditions of the Central Botanical Garden of the National Academy of Sciences of Belarus]. In Biologicheski Aktivnye Veschestva Rasteniy_Izuchenie i Ispol'zovanie [Biologically Active Substances of Plants-Study and Using]; Spiridovich, E.V., Paromchik, I.I., Fomenko, T.I., Eds.; GNU “Central Botanical Garden of the Academy of Sciences of Belarus": Minsk, Belarus, 2013; pp. 76-77. (In Russian)

19. Mihaylova, D.; Vrancheva, R.; Petkova, N.; Ognyanov, M.; Desseva, I.; Ivanov, I.; Popova, M.; Popova, A. Carotenoids, tocopherols, organic acids, charbohydrate and mineral content in different medicinal plant extracts. Z. Nat. C. J. Biosci. 2018, 73, 439-448. [CrossRef] [PubMed]

20. Păltinean, R.; Ielciu, I.; Vlase, L.; Mocan, A.; Gheldiu, A.; Babotă, M.; Vodnar, D.; Crișan, G. Histo-anatomical researches, polyphenolic profile and biological activities of the aerial parts and tubers of Dactylorhiza maculata L. SOÓ. (Orchidaceae). Farmacia 2017, 65, 837-842.

21. Salmerón-Manzano, E.; Manzano-Agugliaro, F. Worldwide Research on Low Cost Technologies through Bibliometric Analysis. Inventions 2020, 5, 9. [CrossRef]

22. Alhajj, M.; Farhana, A. Enzyme Linked Immunosorbent Assay. StatPearls. Available online: https://www.ncbi.nlm.nih.gov/ books/NBK555922/ (accessed on 17 June 2021).

23. Jayaraj, R.; Megha, P.; Sreedev, P. Organochlorine pesticides, their toxic effects on living organisms and their fate in the environment. Interdiscip. Toxicol. 2016, 9, 90-100. [CrossRef]

24. Viljoen, A.; Sandasi, M.; Vermaak, I. The role of the South African Journal of Botany as a vehicle to promote medicinal plant research-A bibliometric appraisal. S. Afr. J. Bot. 2019, 122, 3-10. [CrossRef]

25. Salehi, B.; Sharopov, F.; Martorell, M.; Rajkovic, J.; Ademiluyi, A.O.; Sharifi, M. Phytochemicals in Helicobacter pylori infections: What are we doing now? Int. J. Mol. Sci. 2018, 19, 2361. [CrossRef] [PubMed] 